\title{
TREATMENT OF BACTERIAL ENDOCARDITIS
}

\author{
By IaN G. W. Hill, C.B.E., T.D., M.B., F.R.C.P.E., M.R.C.P., F.R.S.E. \\ Professor of Medicine, Univer sity of St. Andrews
}

In any case of bacterial endocarditis, the result of treatment depends in large measure on the selection of the antibiotic and its administration in a dosage appropriate to the particular organism responsible for the infection. Adequate treatment of this formidable disease, now that potent and selective antibiotics are at our disposal, demands accurate diagnosis, not simply clinical but bacteriological.

\section{Aetiology}

Bacterial endocarditis comprises two very different clinical types, the acute and the subacute. The former, caused by organisms of high virulence such as Staph. aureus or Pneumonocci, is a fulminating rapidly destructive process, occurring usually as part of a general blood infection by the invading organism. The latter is by contrast an insidious, protracted disease, none the less relentless and lethal, caused by a variety of organisms of low virulence. Far and away the most common causative organism is the Streptococcus viridans, which alone accounts for some 85 per cent. or more of the cases (Cates and Christie, I 95I), but in any large series of cases there occurs a proportion due to other organisms. Some are allied species or strains of streptococci ( $S$. salivarius, $S$. faecalis, or Enterococci) so that the proportion of cases due to varieties of non-haemolytic streptococci rises to over 90 per cent. Some strains are microaerophilic or anaerobic, a point which has obvious practical importance in attempted culture and recovery of the organism from the blood of a suspected case. In a few instances the infecting organism is totally distinct from the usual streptococcus, e.g. Haemophilus influenzae, and, in certain parts of Continental Europe at least, Brucella suis.

The sensitivity of these organisms, even between individual strains of the same species of identical cultural types, varies between wide limits. In collected figures for over 400 cases in Britain (Cates and Christie, i95I), $S$. viridans alone showed a range of sensitivity from $1 / 20$ to 300 times the resistance to penicillin of the standard Oxford staphylococcus, a 6000-fold variation. They reported, however, that mor e $\vec{\bullet}$ than four-fifths had a resistance of less than twice $\overrightarrow{\vec{\omega}}$ the standard, and only 4 per cent. were more than ${ }^{\omega}$ eight times as resistant as the standard staphylo- 8 coccus, though in this small proportion the 3 resistance might be formidably high. So also Geraci and Martin (1954) have reported on $33 \omega$ cases of Enterococcus infection in which the $\$$ resistance was generally higher but still was found is to vary considerably; of 39 cultures tested for 0 in vitro sensitivity, only seven were inhibited by less than three units of penicillin per ml., while $\vec{T}$ 17 required over 6 units per $\mathrm{ml}$. and one over $25 \stackrel{\mathbb{D}}{\circ}$ units per $\mathrm{ml}$.

\section{The Importance of Early Diagnosis}

The results of treatment, not as regares mortality alone but in respect of the extent of the residual disability, depend not only on the choice and dosage of antibiotics, and on the duration of treatment, but in very large measure on the stage of the disease at which such treatment is begun. Early diagnosis and prompt and thorough treatment are essential if maximum benefit is to be drawn from the powerful drugs now made available through the genius of Fleming and of those who have followed him. The clinical syndrome of full-blown bacterial endocarditis is well enough known; the crucial point is its early recognition. One must constantly bear in mind the liability of the subjects of rheumatic and congenital cardiac disease to this disorder. In such individuals one must consider it as a possible cause of any febrile episode and more widely; of any vague illness with asthenia, lassitude or anaemia. The $S$. viridans generally gains access $N$ from an oral or dental focus, whether related to diseased and untended teeth or to dental extraction, but it should not be forgotten that other portals of entry exist. The enterococcus, for example, commonly enters through the urinary tract, particularly after operative interference, or through the large bowel. A history of recent tooth extraction or genito-urinary operation, or the presence 
of infective foci in the teeth, throat, or urinary tract, should call to mind the possibility of subacute bacterial endocarditis as a cause of obscure fever or malaise, and should prompt a thorough clinical search for its signs.

\section{The Isolation of the Infecting Organism}

Once the condition is suspected, clinical diagnosis must be supported by intensive effects to isolate the organism. The recovery of the organism and the determination of its sensitivity to individual antibiotics are of fundamental importance. Repeated blood cultures should be done over a period of several days before any antibiotic is started. If penicillin has been given before the patient comes under observation, particularly if in small doses or for a short period, it is justifiable to withhold further treatment for some days, while every effort is made to recover the organism from the blood. Cultures are most likely to be successful if taken when the clinical features suggest that a septicaemic phase is present-malaise or chill and rising fever. A battery of three separate cultures during such an episode commonly yields results in one or other, and such ' salvoes' may be repeated on succeeding or alternate days. Care must be taken in cultural methods to provide for the successful recovery of microaerophilic or anaerobic strains. The addition of ascorbic acid to the blood-broth medium has been advocated, but may through its acidity tend to inhibit growth: my colleagues find addition of meat a satisfactory method. Some workers (Jiminez-Diaz et al. I95I), use plate cultures in addition to liquid media. In any case, the closest collaboration of clinician and bacteriologist is essential; too often a vital matter on which the patient's life may hang is handled in slipshod fashion by junior or ill-informed staff. What can be achieved is shown by the overall positive culture rate of 92 per cent. in the 442 collected cases reported by Cates and Christie (I95I). Persistently negative blood cultures are encountered in a proportion of cases of clinical subacute bacterial endocarditis, even with meticulous care and thoroughness, but the proportion is generally low.

\section{The Choice and Dosage of Antibiotic}

Once an organism has been isolated, and provided there is good reason to believe it is in fact the infecting agent and not a contaminant, the bacteriologist will seek to determine its sensitivity to penicillin, and if necessary to other antibiotics. This sensitivity is reported with reference to that of the Oxford strain of staphylococcus as standard. The variations in sensitivity have been discussed above. It is this test which determines the choice and dosage of antibiotic.

We have seen that the great majority of cases are due to $S$. viridans, and that four-fifths of the strains of this organism have a low resistance to penicillin; in general therefore relatively low daily dosage of penicillin will control such infections, say 2 to 4 million units per day. It will be noted that this scale of dosage is considerably higher than that used in the early trials, when up to half a million units per day was usually employed. In the resistant cases very much higher dosage is called for, sometimes 15 to 50 million units per day. The efficacy of the dose given can be estimated (not without the expenditure of much time and skill) by the bacteriologist, by estimation of the bactericidal or bacteriostatic activity of the patient's serum against a culture of his own organism. In a recent case under one's personal care such test showed inhibition of the infecting organism (an enterococcus) only when 30 million units of penicillin were given daily by continuous intravenous drip. Where extremely high penicillin blood levels are necessary the possibility of attaining these through blocking renal tubular excretion of penicillin should be considered. Caronamide (Dibenamid) acts in such a way, and by its use in doses of $2 \mathrm{~g}$. per day, very high blood levels of penicillin can be maintained with relatively modest daily dosage.

Combinations of antibiotics have been tried by many workers. Of these, perhaps that most generally favoured, particularly in the resistant enterococcus group, is penicillin plus dihydrostreptomycin (Geraci and Martin 1954). The dihydrostreptomycin dose is from $\mathrm{I}$ to $2 \mathrm{~g}$. per day; the penicillin dose is found by close bacteriological control, and averages Io to 15 million units daily though up to 50 million units daily is required on occasion. Others (Jiminez-Diaz et al., 1952), have reported streptomycin in combination with chlortetracycline (Aureomycin) as of value for such enterococcal infections. Similarly other organisms may be encountered which are sensitive to one or other of the tetracyclines; to chloramphenicol or to erythromycin. In general, however, the broadspectrum oral antibiotics are less effective than penicillin alone or with dihydrostreptomycin. In all cases the bacteriologist's in vitro assessment is a valuable guide to dosage.

\section{Duration of Treatment}

There is now no doubt that the duration of antibiotic treatment is also of prime importance in the successful management of this disease. The duration of treatment is in fact as important as the level of daily dosage, as a consideration of the reports of early trials of penicillin in subacute 
bacterial endocarditis will confirm. In such trials around 1945-46, when penicillin was scarce and expensive, small daily quotas were administered for from Io to 2 I days; the initial effects on pyrexia, etc. were dramatic, but relapse was practically invariable. More recently, with ample supplies of penicillin available, an attempt to treat cases with a short ro-day course, using up to I4 million units per day, bolstered by Caronamide, has shown conclusively the futility of such a regime, only one of eight patients in the series being cured by this course (King et al., 1948, quoted by Beeson, 1955). Gradually over the years it has come to be recognised that moderate daily doses ( $\frac{1}{2}$ to 2 million units) continued for 28 days or longer yield far better rates of cure, till now it is usual to prescribe a 56-day course of antibiotic as routine. The decision as to the minimum duration of treatment should be taken at the start of antibiotic therapy, and should be adhered to no matter how prompt and dramatic the initial effects may be. It is tempting after say three weeks of apyrexial uneventful progress to yield to the importunities of a harassed patient, and to cut short the tedious sequence of frequent daily injections, with all the attendant discomfort or pain. Such curtailment of the planned course is, however, fraught with danger to the patient from the risk of relapse, a risk which is the greater the earlier the course is abandoned. It is wiser at the outset, so soon as the patient feels the benefit of the first few injections, to explain to him the necessity for thorough and prolonged treatment, and to gain not only his consent but his willing co-operation. Should clinical relapse occur during the actual course, the dosage and nature of the antibiotic should be reconsidered in the light of any fresh bacteriological data, and the total duration of treatment correspondingly extended.

It should be noted that attempts are still being made to find some way to cut short this irksome and expensive regimen, following much the same lines as have been tried in respect of anticoagulant treatment in coronary occlusion. In the latter, attempts have been made to recognize "good risk' and 'poor risk' cases, with limitation of anticoagulant treatment to the latter. So, too, in subacute bacterial endocarditis, some physicians group patients with a short pre-treatment illness and fully sensitive organism as suitable for a shortened, though intensive course of treatment, lasting two to four weeks only (Beeson, 1955). This modification has proved satisfactory in certain instances, but the writer would deprecate its adoption on any wide scale at present. As Beeson wisely states (loc. cit.) ' in a disease of such gravity conservatism is certainly proper, and all would agree that any error should be in the direction of overly long treatment.'

\section{Special Varieties of Subacute Bacterial Endocarditis}

I. The abacterial case, that is one in which al $\overrightarrow{\overrightarrow{\hat{\sigma}}}$ attempts to recover the organism from the blood prove fruitless, demands further attention. Suclo cases represent a small percentage only of the totap. (under ro per cent.), but do occur in spite of the most careful and assiduous attempts at blood culture. At autopsy in many, typical subacute bacterial endocarditis vegetations are found and $\vec{P}$ organisms have even been demonstrated in $\vec{t}$ sections of, or by culture from, the lesions Cates and Christie (195I), review the cases of this type in their collected series, and point.out thei] poor response in general to penicillin, and the highi mortality in the group ( 82 per cent.). It is generally agreed that such abacterial cases requires more intensive therapy than those in which a fullye sensitive organism is recovered, say 5 million units penicillin or more daily for at least six to eigh? weeks. This may be combined with advantage with dihydrostreptomycin.

2. Subacute Bacterial Endocarditis in Congenitat్ Heart Disease. In Cates and Christie's large series of cases of bacterial endocarditis I I per cebt $\vec{c}$ arose in cases of congenital heart disease and these about one quarter were in patients wo patent ductus arteriosus. The risk of such ano infection developing sooner or later in patients with this lesion is such that deliberate ligature of the ductus in the healthy child is justified, and is ino fact current practice. In the series quoted about half the congenital heart cases are noted as arisingo in association with ventricular septal defect but ${ }^{3}$ in view of the recent recognition of the fallacies in the clinical diagnosis of ventricular septal defect from pulmonary stenosis and other lesions, this figure may be misleading and should be viewed with:reserve. The diagnosis of subacute bacterial endo- 3 . carditis in congenital heart disease may presento difficulty, especially if the vegetations are located at 3 a defect causing a left-to-right shunt. In that event emboli are swept into the pulmonary circulation? instead of to the systemic blood vessels as in theo rheumatic mitral or aortic case. On occasion many months may be lost by the unwary in treatingo ' recurrent patchy pneumonia' when in reality then lung lesions are embolic from an infected patent N ductus arteriosus.

In the management of a patient with an infected ductus we are faced with a choice of measures: simple antibiotic treatment as in acquired heart $\stackrel{?}{+}$ disease; operative ligation of the infected com- 0 municating channel; or a combination of anti- 


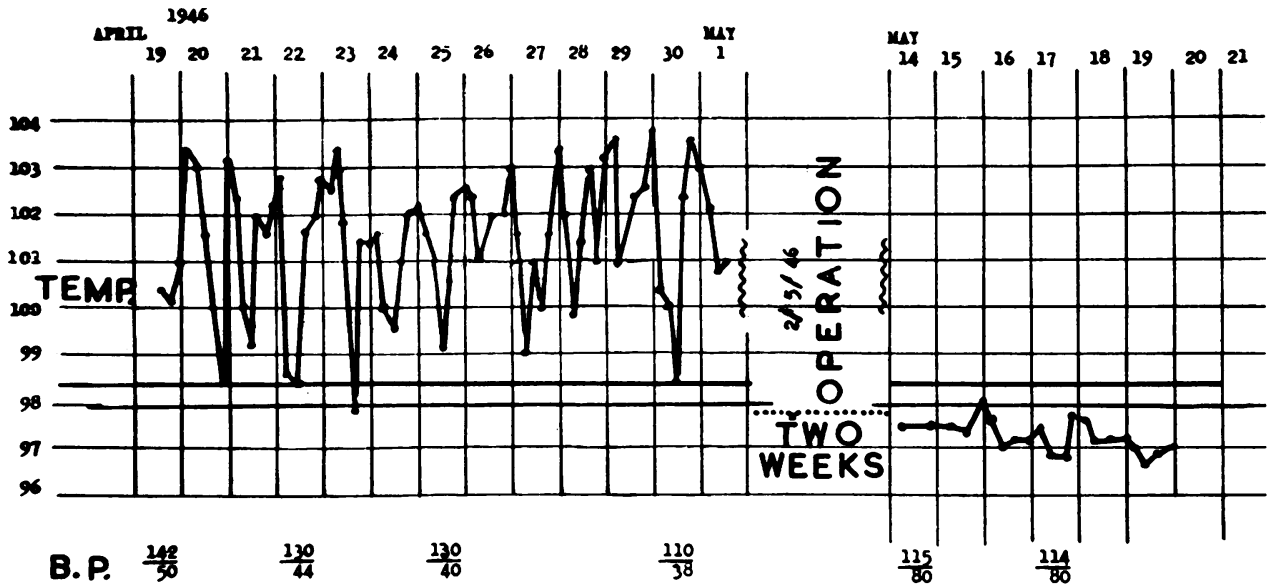

\section{LIGATION OF INFECTED DUCTUS ARTERIOSUS.}

FIg. I.-Female, I6 years. Subacute endarteritis in patent ductus arteriosus. Onset of symptoms eight days before admission. Blood cultures repeatedly positive for $S$. viridans, fully sensitive to penicillin. Operation and ligation of ductus $2 \mathrm{I}$ days after onset without antibiotic treatment. Immediate abolition of pyrexia; subsequent blood cultures all negative. End-result highly satisfactory. (By courtesy of Dr. A. Rae Gilchrist.)

biotics and surgery. The great advantage of ligation over antibiotic therapy lies in the fact that the further emboli from the ductus are prevented, a benefit which antibiotics have no power to confer. Gilchrist and Mercer (1947) have published their experiences in a series of cases, from which it is clear that simple ligation of the ductus may lead to clinical cure, without the aid of antibiotics. Fig. I, reproduced from the data of one of their cases, illustrates this point. In this patient blood cultures performed on the operating table yielded colony counts of 16 and 30 per mil., the latter from a sample taken three minutes after the ligatures on the ductus were tied. Subsequent cultures, from I6 minutes after ligature onwards, were negative. The dramatic resolution of fever is illustrated in the figure. The subsequent course of this patient was satisfactory (Gilchrist, 1955). Satisfactory as such simple ligation can be in skilled hands, however, the surgical risks in the infected case are formidable and in general the approach to such cases is usually by a combined attack. Antibiotic treatment is given to control the bacteraemia and infection, failure if present is controlled, and ligation carried out as soon as the patient's condition permits.

\section{Focal Sepsis in Established Subacute Bacterial Endocarditis}

The urgency of treating the grave cardiac infection may readily overshadow the need in such cases to search for, and if possible, eradicate focal infection. The focus in teeth or elsewhere which afforded a portal of entry to the original infection may continue to harbour the organism, and may act as a reservoir of infection. Failure to search for and deal radically with a dental root abscess, for example, may lead to repeated reinfection during treatment, or to early relapse when the antibiotic course is discontinued. In an ill patient a difficult decision may have to be made when the evils of such a persistent nidus of infection have to be weigh $2 d$ against the ris'ss of dental or other operations, possibly involving general anaesthesia.

\section{Prognosis with Treatment}

Despite the powerful and specific remedies now available, and notwithstanding the contributions made by skilled bacteriological aid, the overall mortality in most reported series remains disappointingly high, at around 50 per cent. A review of the causes of death and the known factors influencing the death rate is therefore necessary.

In the first place, in rheumatic cases major systemic embolism involving especially the cerebral arteries, but on occasion others (coronary, mesenteric or limb), and with underlying congenital heart disease pulmonary embolism are very common. Such embolic accidents are a major cause of death, and constitute a risk in treated cases quite independent of successful bacteriostasis. An example is shown in Fig. 2., in which fatal cerebral embolism occurred in a patient I I days after the start of penicillin treatment, and when the clinical response had been excellent. This patient had long-standing lesions, and had had minor cerebral seizures, probably embolic in origin, for many 
MRS.MS, 27.

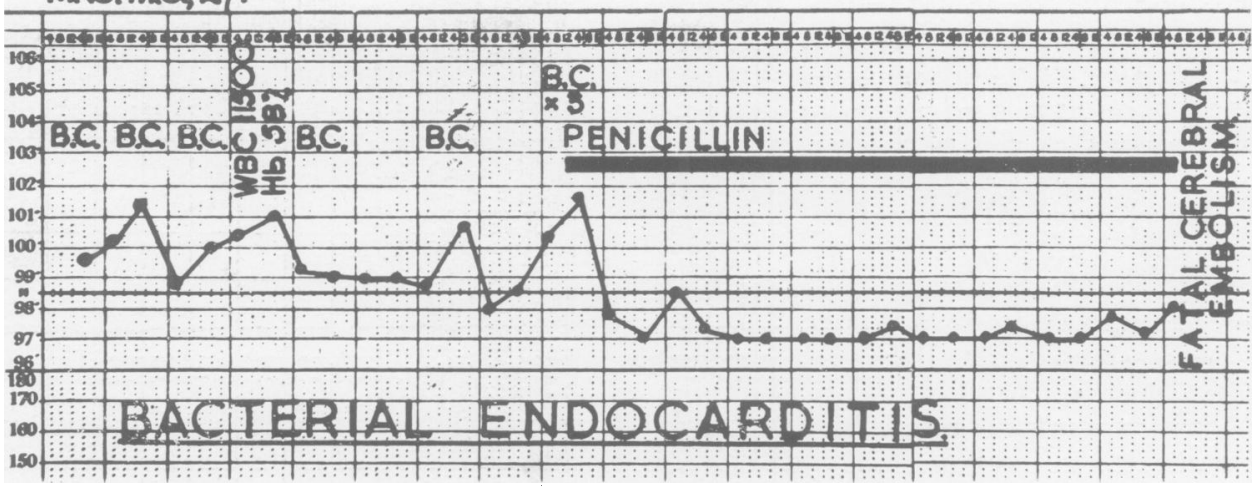

FIG. 2.-Female, 27 years. Admitted as suspected bacterial endocarditis. Presenting symptom cerebral episodes probably embolic, occurring over many months. Blood cultures repeatedly positive for $S$. viridans, fully sensitive. Treated with penicillin with dramatic response in reduction of fever and increased well being. Sudden death I I days later. Post mortem showed cerebral embolism.

months before coming under observation and treatment. While such grave emboli are most frequent in long-standing cases of this type they do occur in a proportion of early cases. They may occur also late in the course of treatment and as explanation it has been suggested that embolism from orgarizing healing vegetations is more likely to be massive than that from soft friable active lesions. The combination of anticoagulant treatment (heparin) with antibiotics has not proved of value in prevention. Embolic deaths occur in about Io to I 5 per cent. of treated cases.

Secondly the development of cardiac failure may lead to a fatal issue, or in survivors may lead to gross residual disability. Cases already in failure when treatment is started do very badly, as do those developing it under treatment. Such failure may be caused by profound toxaemia poisoning the myocardium, or may be a sequel to gross destruction of cusps and valve apparatus (chordae, etc.). It is more likely to develop in cases brought late under treatment, but can occur in promptly treated patients. Such a case is figured (Fig. 3), in which it is probable that a very severe infection caused rapid disorganization of the affected valve. This patient, known to have moderate asymptomatic aortic stenosis, developed a bacterial endocarditis, the symptoms starting acutely with a rigor. Blood cultures on the $5^{\text {th }}$ and 6 th days were sterile. Two blood cultures seven days later after the onset yielded respectively Strep. viridars and Staph. aureus; a culture next day gave again Staph. aureus. The staphylococcus was coagulase positive. All the organisms were fully sensitive to penicillin and this antibiotic was given for 56 days, for the first II days at 4 million units per day and thereafter at 8 million units per day.
Rapid control of bacteraemia and fever was $\stackrel{0}{\mathrm{c}}$ achieved and he made a good recovery, but hiso physical signs changed to those of gross aortic incompetence. On his return from a convalescent 7 home three months later he already had early은

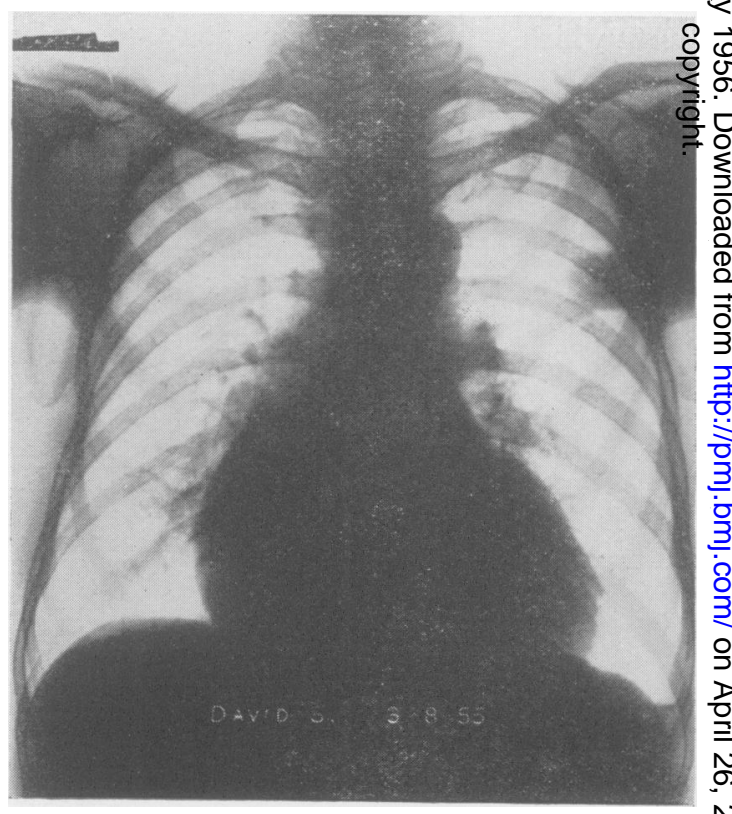

Fig. 3.-Male, 45 years. Admitted with short history suggesting bacterial endocarditis in a known case of $\omega$ aortic stenosis. Blood cultures showed $S$. viridans once and Staph. aureus on two occasions. Excellente response to penicillin to which the organisms were $\frac{C}{D}$ fully sensitive. In convalescence developed con- $\mathbb{D}$ gestive cardiac failure which has progressed and persisted. X-ray I 6 months later showing gross cardiac enlargement. 
congestive failure, and this progressed to gross and resistant anasarca. The heart became grossly enlarged (Fig. 3). Without doubt irreparable destruction of the valve resulted from this infection.

Treatment of such cardiac failure follows standard lines, and will not be detailed here.

Uncontrolled infection leads of course to a fatal issue, and occurs in a proportion of cases despite heroic doses of antibiotics. It has been thought to be more liable to occur in previously treated cases who have relapsed and, in whom a degree of penicillin resistance may develop. This risk may have been exaggerated, at least in frequency, for Cates and Christie (I95I), found few cases showing such acquired resistance among their relapsed cases, and others have had similar experiences. It has been demonstrated to occur, however, in some cases and from analogy with the development of resistant strains of organisms in other diseases it would appear a potential danger. All that has been said above regarding identification and sensitivity testing of organisms, and regarding dosage and duration of treatment, has a bearing here.

A fourth major cause of death is cachexia. It has been clearly demonstrated that the patient who comes under treatment in a poor nutritional state or in cachexia has a poor outlook as regards survival. Such patients, like those in cardiac failure, are generally those in whom the lenta form of the comes under treatment in a poor nutritional state, or incachexia, has a poor outlook as regards survival. Such patients, like those in cardiac failure, are generally those in whom the lenta form of the disease has grumbled on, undiagnosed, for several months. The key to prevention of such deaths is early diagnosis. It is implicit of course that in the management of all cases full attention be given to adequate food intake, with emphasis on easily assimilable protein in quantity sufficient to conserve tissue proteins during the febrile phase.

There are other dangerous if less frequent hazards besetting the course of the victims of bacterial endocarditis-mycotic aneurysm formation and rupture; piecemeal renal destruction leading to uraemia, etc. Only one further complication will however be considered in any detail-relapse and/or reinfection. Clinical relapse with pyrexia, petechiae, minor embolic signs and the whole familiar syndrome of active subacute bacterial endocarditis is unfortunately fairly frequent. Its incidence is less when antibiotic treatment has been under skilled bacteriological control, where possible foci of infection have been eradicated, and where the dosage and duration of treatment have been generous and prolonged. Despite meticulous care, however, relapse cases

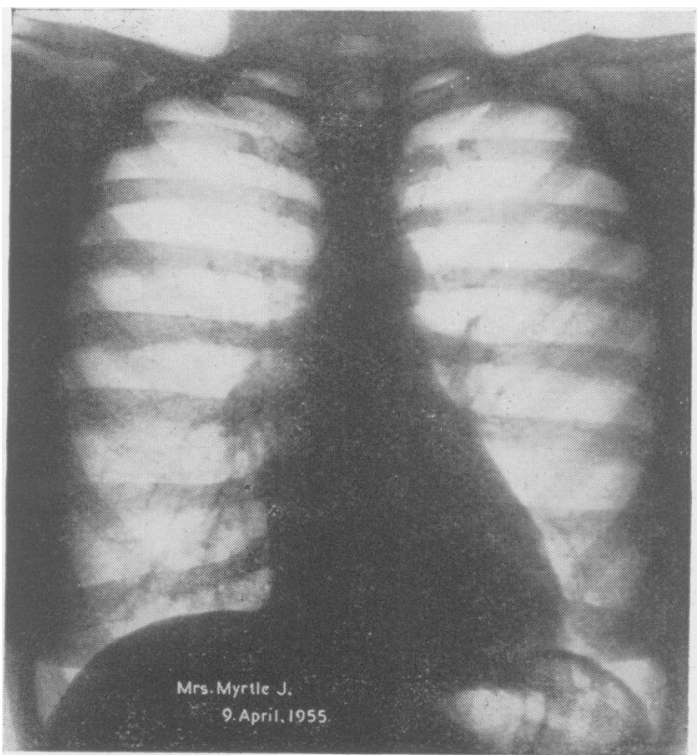

FIG. 4.-By contrast with Fig. 3. X-ray of a female patient 26 years old after successful treatment of bacterial endocarditis. Onset six weeks before blood cultures were done in hospital. These yielded repeatedly $S$. viridans which was fully sensitive. Treatment by 5 million units penicillin daily for 54 days, followed by benzanthine penicillin orally.

do occur, and the possibility must always be foreseen and precautions taken. It is true that relapse, if it occurs, comes as a rule fairly early in convalescence, generally within the first month. While the risk is greatest in the first few weeks, late relapse or reinfection is by no means uncommon. Follow-up of treated survivors is thus an integral part of the management of the disease, and is the responsibility alike of the patient's own doctor and the hospital physician. It is particularly important in patients whose infecting organism is known to have been more than usually resistant.

To sum up the results of treatment, a low mortality and good functional end-results can be expected in patients who come early under treatment, who are young and well nourished, not in failure, and in whom a fully sensitive organism is isolated (Fig. 4). Conversely, where the patient is older (over 40), comes late to diagnosis, or has a resistant organism or an ' abacteraemic' infection, the death rate is higher and the end-results in survivors are much less satisfactory. When cardiac failure is present or develops under treatment, or where the patient is already cachectic, the outlook is very poor, notwithstanding vigorous and skilful antibiotic treatment.

Bibliography continued on page 120. 
and tenable for two years (with possible extension to three years at the discretion of the Senatus Academicus), will be open for award in October 1956. The Fellowship is open to graduates of any University. The holder will be required to carry out approved research work in surgery and/or medicine in the University, and he must attend the honours class in physiology, unless he is already a graduate in physiology or in science. While undertaking the research work he will be expected to maintain contact with clinical work, but the time to be devoted to this will be restricted to two half-days per week. During his tenure the Fellow will not be permitted to study for or to present himself for any examination leading to a higher diploma in medicine or surgery. Applications must be submitted on a prescribed form, a copy of which may be obtained from the Dean of the Faculty of Medicine, or from the undermentioned persons.

Applications from graduates in the United Kingdom must be received by March I, I 956, addressed to Dean, Faculty of Medicine, University New Buildings, Edinburgh, 8, Scotland.

The Ernest and Minnie Dawson Cancer Trust. Under the provisions of the Trust Deed a competition will take place in 1956 and will be in the form of a thesis on 'Cancer; its early diagnosis, causes, prevention and treatment.' 'The competition is open to all general medical practitioners practising and/or residing in Lancashire or Yorkshire, and the prizes offered are $\oint_{1}, 500$ (first) and $£_{500}$ (second) subject to the merit of the entries submitted.

Further details and conditions of entry can now be obtained from the Clerk to the Trust, The Ernest and Minnie Dawson Cancer Trust, 89a Fishergate Hill, Preston, Lancs.

Association of Surgeons of Great Britain and Ireland. The Annual Meeting will be held in London on Thursday, Friday and Saturday, April 19, 20 and 2 I, 1956.

Full particulars from the Honorary Secretary, Association of Surgeons of Great Britain and Ireland, 45 Lincolns Inn Fields, London, W.C.2.

Ophthalmological Society of the United Kingdom. The Annual Congress will be held at the Royal Society of Medicine, I Wimpole Street, London, W.I, on April 26, 27 and 28, 1956.

Full particulars from the Honorary Secretary, The Ophthalmological Society of the United Kingdom, 45 Lincolns Inn Fields, London, W.C.2.

Rogers Prize. This prize will be awarded by the Trustees 'To such person as in their opinion shall have written the best or only good essay on the treatment of the sick poor of this country, and the preservation of the health of the poor in this country, or either of such subjects,' power being reserved to the Trustees to withhold the award of the prize if no essay shall have been submitted which, in their opinion, merits a prize. The competition is an open one; the treatment of the subjects and the length of the essay are left to the discretion of the essayist. Persons desirous of competing for the prized which, it is estimated, will amount to about fro5, are invited to submit essays not later than May I, I956.

Full particulars from the Clerk to the Trustees, Society of Apothecaries, Black Friars Lane, Queen Victoria Street, London, E.C.4.

Experimental Research into Problems of Ageing Candidates are invited to submit papers descriptive of

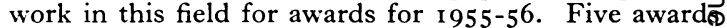
of an average value of $£ 300$ each are available for the period 1955-56; the announcement of awards will bf made in July, 1956. Entries must be received not later. than February 10, I 956, and the work submitted shoul $\$$ not have been published before July 31 , 1955. Paper $\overrightarrow{\underline{\mathbf{s}}}$ should not be more than 7,000 words in length and maw be in the candidate's own language.

Full particulars are obtainable from the Director, Cib Foundation, 4I Portland Place, London, W.r.

Health Congress. The Royal Society for the Promotiof of Health Congress will take place in Blackpool front April 24 to 27,1956 .

For further information application should be made to the Secretary, The Royal Society of Health, 90 Buckingt ham Palace Road, London, S.W.I.

British Association of Urological Surgeons, Hom and Overseas. The Annual Meeting will be held if Liverpool on June 28,29 and $30,1956$.

Full particulars from the Honorary Secretary, Britis Association of Urological Surgeons, Home and Overseaฏ 46 Lincoln's Inn Fields, London, W.C.2.

Anglo-French Exchange Bursaries. Applications $\overrightarrow{\mathrm{g}} \overrightarrow{\mathrm{G}}$ now invited for the bursaries which will be awarde $\$$ ig 1956 to young British doctors under the exchange scheme arranged by the French Embassy in Longof between the Institut d'Hygiene in Paris and the Cib Foundation in London. The value of the French grants is $60,000 \mathrm{fr}$. a month, tax free, and they will be awarde for periods of two to four months to medical men who wish to obtain clinical experience or carry out researc $\mathbb{B}$ in France. Since the aim of the exchange is to spread in each country knowledge of achievements, outlook and methods on the other side of the Channel, preference will normally go to candidates who are in teaching in posts where they can pass on the experience they have acquired. The British selection board is composed as follows: Prof. Alexander Haddow, Prof. Joh McMichael and representatives of the British Counc (Dr. Margaret Suttill), the British Postgraduate Medic Federation (Dr. C. F. Hamilton Turner), the Medica Research Council (Dr. F. J. C. Herrald) and DE G. E. W. Wolstenholme (Ciba Foundation).

Application forms may be obtained from $\mathrm{Dr}$. Wolstenholm Ciba Foundation, 4I Portland Place, London, W.I. The closing date for applications is February 4, 1956.
Bibliography continued from page 97 . BIBLIOGRAPHY

BEESON, P. B. (1955), Amer. F. med., 19, I.

CATES, J. E. and CHRISTIE, R. V. (I95I), Quart. $\mathcal{F}$. Med., 20, 93. CHRISTIE, R. V. (1946), Brit. med. $\mathscr{f}$., i, $38 \mathrm{r}$

GERACI, J. E. and MAR'TIN, W. J. (I954), Circulation, 10, 173.
Ian G. W. Hill, C.B.E., T.D., M.B., F.R.C.P.E., M.R.C.P., F.R.S.E.

GILCHRIST, A. R. (1955), Personal communication. GILCHRIST, A. R. and MERCER, W. (r947), Lancet, ii, 267. JIMINEZ-DIAZ, C., ARJONA, E. and ALES, J. M. (1952 D Cardiologia, 21, 687 . TALSSIG, H. V. and BAUERFELD, S. R. (1952), Ibid., 21, 5 4 